\title{
Inorganic material for high speed write-once FVD disc
}

\author{
Ting-Hau $\mathrm{Wu}^{\mathrm{a}, *}$, Jung-Po Chen ${ }^{\mathrm{b}}$, Chih-Yuan $\mathrm{Wu}^{\mathrm{b}}$, Po-Fu Yen ${ }^{\mathrm{b}}$, Ching-Yu Hsieh ${ }^{\mathrm{b}}$, \\ Tzuan-Ren Jeng ${ }^{\mathrm{b}}$, Po-Cheng Kuo ${ }^{\mathrm{a}}$, Der-Ray Huang ${ }^{\mathrm{b}}$, Sheng-Chi Chen ${ }^{\mathrm{c}}$ \\ ${ }^{a}$ Institute of Material Science and Engineering, National Taiwan University, Taipei 106, Taiwan \\ ${ }^{\mathrm{b}}$ Opto-Electronics \& Systems Laboratories, Industrial Technology Research Institute, Bldg. 78, 195 Sec. 4, Chung Hsing Rd., Chutung, \\ Hsinchu, Taiwan 310, ROC \\ ${ }^{\mathrm{c}}$ Department of Materials Engineering, Mingchi University of Technology, Taipei 243, Taiwan
}

Available online 5 April 2006

\begin{abstract}
A new inorganic recording media is introduced for write-once type forward versatile disc. Experimental result shows that the recording characteristics of jitter are obtained to be $5.5 \%$ at $18.5 \mathrm{~mW}, 6.1 \%$ at $25 \mathrm{~mW}$ and $7.2 \%$ at $32 \mathrm{~mW}$, respectively, for $4 \times, 8 \times$ and $12 \times$ recording speed with track pitch of $0.74 \mu \mathrm{m}$. And the recording characteristics of jitter are obtained to be $7.27 \%$ at $19 \mathrm{~mW}$ and $7.55 \%$ at $25.5 \mathrm{~mW}$, respectively, for $4 \times$ and $8 \times$ recording speed with track pitch of $0.64 \mu \mathrm{m}$.

(C) 2006 Elsevier B.V. All rights reserved.
\end{abstract}

PACS: $42.79 . \mathrm{Vb}$

Keywords: Optical disc; Write-once; Inorganic; High speed

\section{Introduction}

Optical disc becomes a common product due to the advantage of low price and exchangeability. Although the write-once-type DVD-R disc is so popular, organic dye as recording media brings more environmental issues.

A new optical disc format with $650 \mathrm{~nm}$ laser and track pitch of $0.64 \mu \mathrm{m}$, so called the forward versatile disc (FVD), has been proposed by Taiwan Advanced Optical Storage Research Alliance to store more data than DVD. For a single-layer FVD disc its physical storage capacity receives $5.4 \mathrm{~GB}$.

Several inorganic types write-once recording materials, such as $\mathrm{AgOx}[1], \mathrm{Te}-\mathrm{O}-\mathrm{Pd}$ [2], $\mathrm{Si} / \mathrm{Cu}$ [3], $\mathrm{Ge}-\mathrm{Bi}-\mathrm{N}$ [4] and $\mathrm{Si} / \mathrm{Al}[5]$ have been proposed in the prior study on writeonce optical discs. In this paper, germanium aluminium bimetal layers as write-once recording material are applied for high-speed write-once FVD disc. After optimizing the layer structure, the new write-once disc is acceptable for high recording speed.

\footnotetext{
*Corresponding author. Tel.: + 886223648881 ; fax: + 886223634562

E-mail address: D91527004@ntu.edu.tw (T.-H. Wu).
}

\section{Experiments}

Fig. 1 shows the cross-sectional view of the invented write-once disc. Firstly, three $0.6 \mathrm{~mm}$ polycarbonate substrates with track pitch of $0.74,0.68$ and $0.64 \mu \mathrm{m}$ were prepared, respectively. Then, a disc structure in the order of a lower protective layer $\left(\mathrm{ZnS}-\mathrm{SiO}_{2}\right)$, a recording bimetal layer stack (Ge layer and $\mathrm{Al}$ layer), an upper protective layer $\left(\mathrm{ZnS}-\mathrm{SiO}_{2}\right)$ and a reflective layer $(\mathrm{Ag})$ were deposited on those substrates by commercialized sputtering system (Modulus, SINGULUS). Finally, each deposited substrate was bonded with a dummy substrate of $0.6 \mathrm{~mm}$ thickness.

Bi-layer films of $\mathrm{Ge} / \mathrm{Al}$ was deposited on silicon wafer as test sample to investigate the phase transition temperature $\left(T_{c}\right)$, and the relationship between reflectivity and temperature at different heating rates was measured. Crystalline structure of the $\mathrm{Ge} / \mathrm{Al}$ bi-layer films is observed by transmission electron microscope (TEM) and X-ray diffraction (XRD) meter. The composition of the Ge/Al films are found from the energy dispersive spectrometer (EDX).

The jitter values and modulations were evaluated to present its performances by using a dynamic tester 


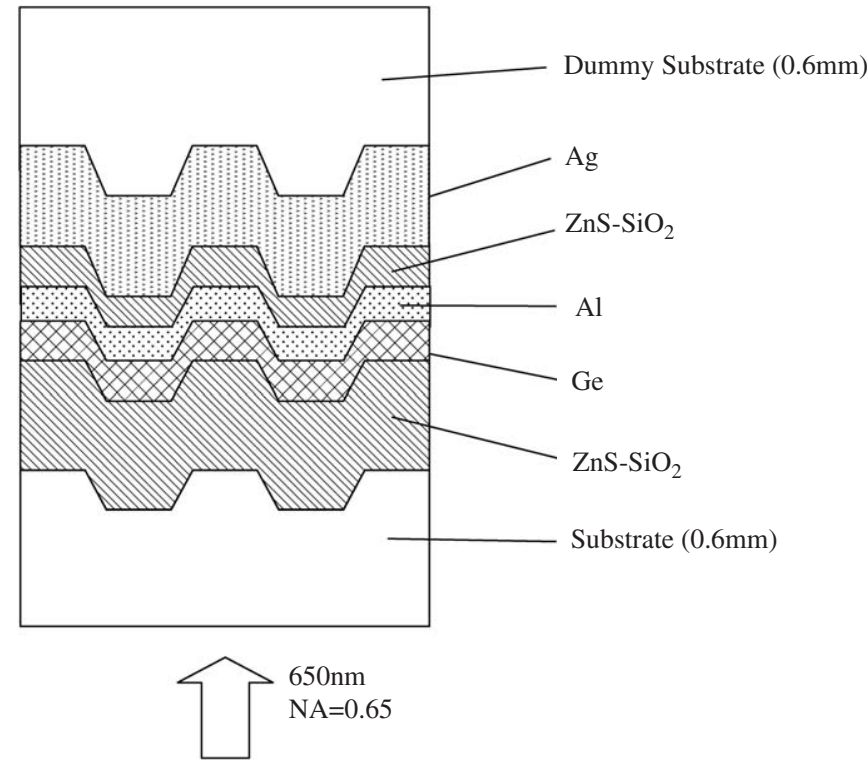

Fig. 1. Cross-sectional view of the write-once disc.

Table 1

Evaluation conditions

\begin{tabular}{ll}
\hline User capacity & $4.7 \mathrm{~GB} / 5.1 \mathrm{~GB} / 5.4 \mathrm{~GB}$ \\
\hline Thickness of substrate & $0.6 \mathrm{~mm}$ \\
Wavelength & $650 \mathrm{~nm}$ \\
NA & 0.65 \\
Modulation code & $8 / 16$ \\
Track pitch & $0.74 \mu \mathrm{m} / 0.68 \mu \mathrm{m} / 0.64 \mu \mathrm{m}$ \\
Recording format & Groove
\end{tabular}

(ODU1000, PULSTEC). The wavelength of the laser beam is $650 \mathrm{~nm}$ and the numerical aperture (NA) of the objective lens is 0.65 . The evaluation conditions are summarized in Table 1 . The modulation code is $8 / 16$ as DVD. The data was recorded and evaluated on the groove area. The linear velocities are 14,28 and $42 \mathrm{~m} / \mathrm{s}$ with respect to $4 \times, 8 \times$ and $12 \times$ recording speed.

\section{Results and discussion}

The relationship between reflectivity and temperature at different heating rates is shown in Fig. 2. The reflectivity has a rapidly change at temperature $T_{c}$. Fig. 2 shows the phase transition temperatures are $259-262^{\circ} \mathrm{C}$ at different heating rate.

Fig. 3 shows the XRD patterns of the as-deposited and initialized $\mathrm{Ge} / \mathrm{Al}$ disks (with $\mathrm{Ag}$ reflective layer). It reveals that the as-deposited $\mathrm{Ge} / \mathrm{Al}$ bi-layer is amorphous (only $\mathrm{Ag}$ (1 11 1) of reflective layer is found), after being initialized by laser power, $\mathrm{Ge}_{3} \mathrm{Al}_{7}(200)$ peak appeared. The preferred crystal orientation resulted from nano-scale thickness of the recording layer. Fig. 4(a) and (b) shows the bright field images of the as-deposited and annealed $\mathrm{Ge} / \mathrm{Al}$ films (without $\mathrm{Ag}$ reflective layer). It is annealed at $280^{\circ} \mathrm{C}$ for $30 \mathrm{~min}$ and then quenched in ice water. The difference

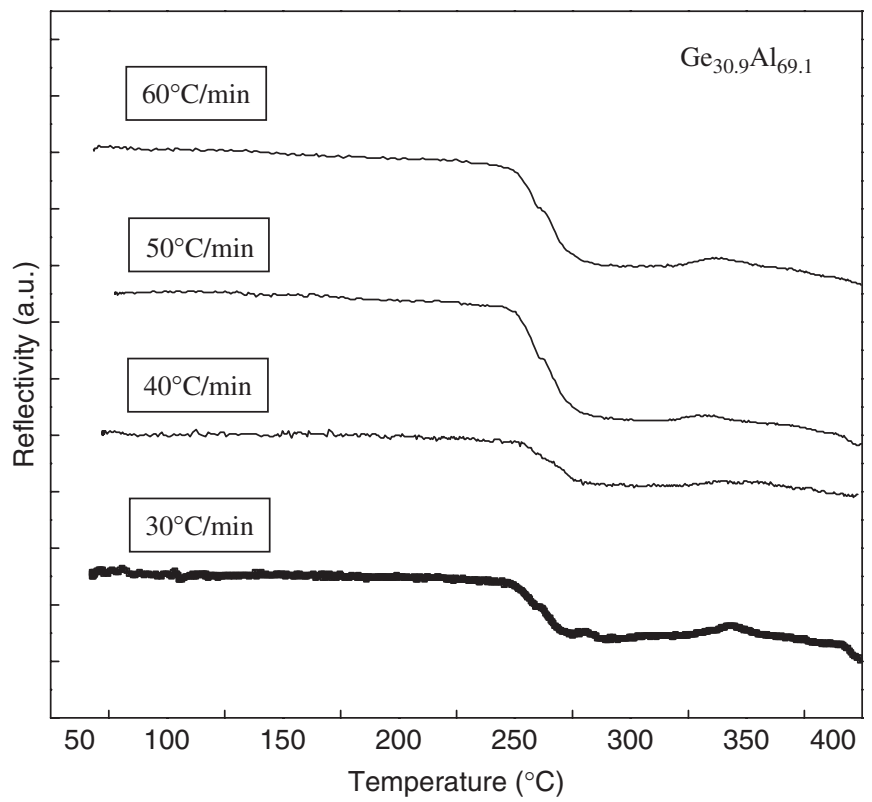

Fig. 2. Reflectivity as a function of temperature under four different heating rates.

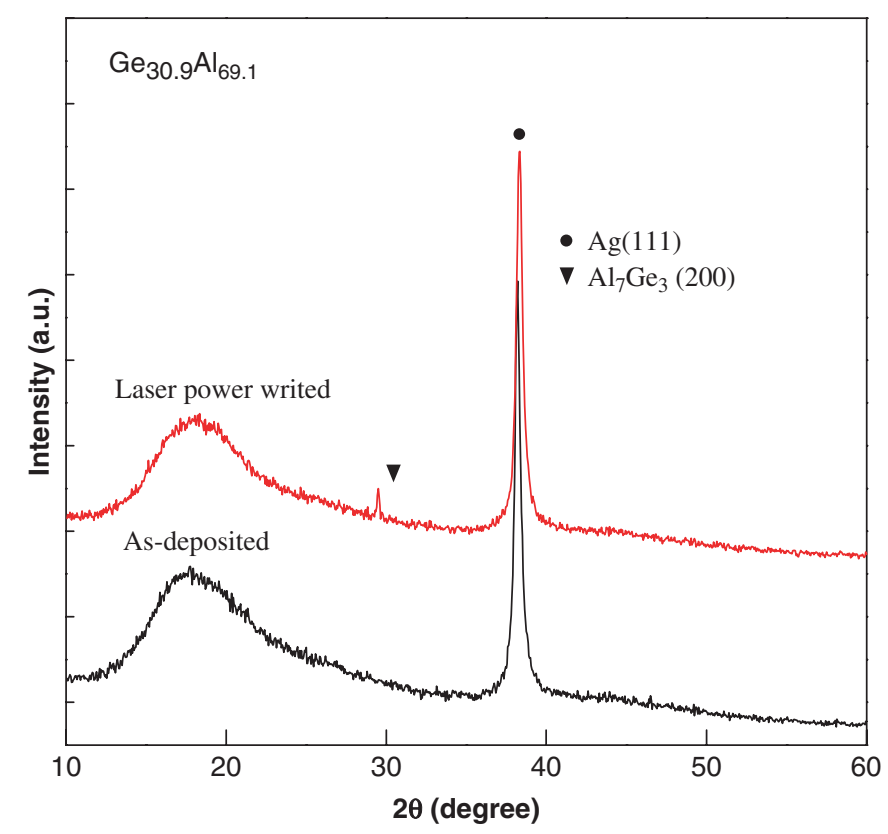

Fig. 3. X-ray diffraction patterns of the as-deposited and initialized.

between the XRD and TEM investigation is that the TEM ring pattern of the as-deposited $\mathrm{Ge} / \mathrm{Al}$ film has clearly diffraction rings which identifies as $\mathrm{Ge}_{3} \mathrm{Al}_{7}(200)$ and $\mathrm{Ge}_{3} \mathrm{Al}_{7}(020)$. Those are the same as the annealed $\mathrm{Ge} / \mathrm{Al}$ films. This means that the as-deposited $\mathrm{Ge} / \mathrm{Al}$ bi-layer already has crystalline structure at the Ge/Al interface. Due to poor resolution, any crystalline peaks in the asdeposited Ge/Al films cannot be found from XRD data. After annealing at $280^{\circ} \mathrm{C}$ for $30 \mathrm{~min}$, the grains in the interface grow to the whole volume of the recording layer. The mechanism of interface induced grain growth makes 

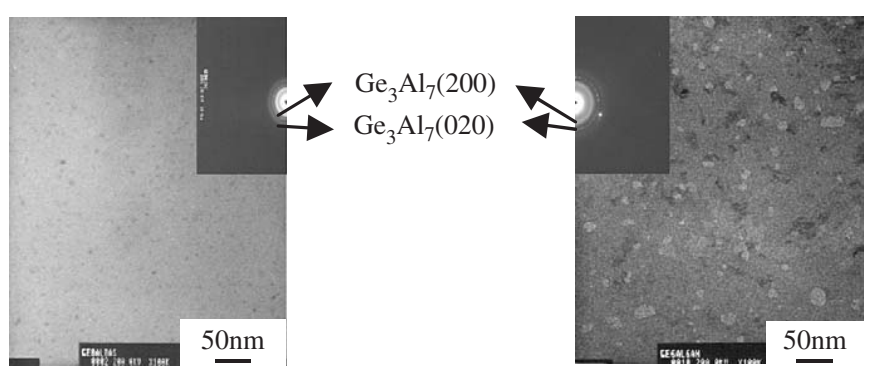

Fig. 4. TEM bright field images and ring patterns of the $\mathrm{Ge} / \mathrm{Al}$ films, (a) as-deposited and (b) annealed at $280^{\circ} \mathrm{C}$ for $30 \mathrm{~min}$.

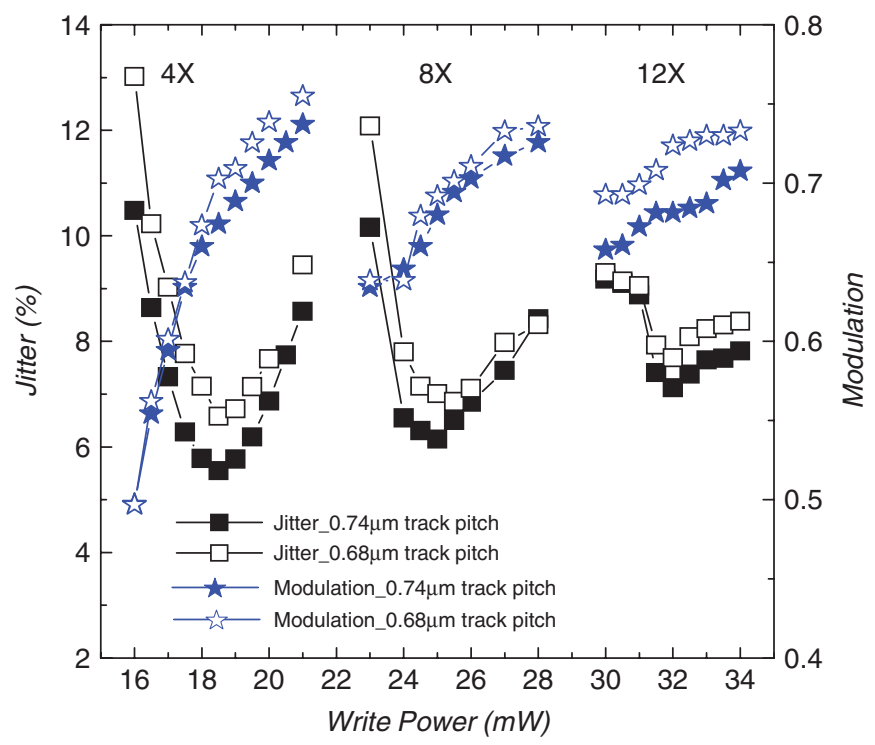

Fig. 5. Write power characteristics of jitter and modulation for discs with track pitch of 0.74 and $0.68 \mu \mathrm{m}$.

the $\mathrm{Ge} / \mathrm{Al}$ films to be a low jitter value at high-speed recording. The composition of $\mathrm{Ge} / \mathrm{Al}$ bi-layer identified by $\mathrm{EDX}$ is $\mathrm{Ge}_{30.9}: \mathrm{Al}_{69.1}$ which is near the eutectic point in the $\mathrm{Ge}-\mathrm{Al}$ phase diagram.

Its recording characteristic is investigated under different recording powers and recording speeds, as shown in Fig. 5.
The optimum jitters are found to be $5.5 \%$ at $18.5 \mathrm{~mW}$, $6.1 \%$ at $25 \mathrm{~mW}$ and $7.2 \%$ at $32 \mathrm{~mW}$, respectively, for $4 \times$, $8 \times$ and $12 \times$ recording speed with track pitch of $0.74 \mu \mathrm{m}$. The optimum jitters are $6.58 \%$ at $18.5 \mathrm{~mW}, 6.86 \%$ at $25.5 \mathrm{~mW}$ and $7.69 \%$ at $32 \mathrm{~mW}$, respectively, for $4 \times, 8 \times$ and $12 \times$ recording speed with track pitch of $0.68 \mu \mathrm{m}$. And the optimum jitters are $7.27 \%$ at $19 \mathrm{~mW}$ and $7.55 \%$ at $25.5 \mathrm{~mW}$, respectively, for $4 \times$ and $8 \times$ recording speed with track pitch of $0.64 \mu \mathrm{m}$. The modulations are almost greater than 0.6 . It proved the recording feasibility of germanium aluminium bi-metal thin film for high speed write-once FVD disc.

\section{Conclusion}

An inorganic write-once media constituted from $\mathrm{Ge} / \mathrm{Al}$ bi-metal thin film, was introduced for FVD-R in this paper. The interface-induced crystallization mechanisms are found by XRD and TEM. The grains of $\mathrm{Ge}_{3} \mathrm{Al}_{7}(200)$ and $\mathrm{Ge}_{3} \mathrm{Al}_{7}(020)$ are identified at $\mathrm{Ge} / \mathrm{Al}$ interface in the as-deposited film. After annealing at $280{ }^{\circ} \mathrm{C}$ for $30 \mathrm{~min}$, the grains in the interface grow and diffuse to the whole volume of the recording layer. And the recording characteristics of jitter are obtained to be $7.27 \%$ at $19 \mathrm{~mW}$ and $7.55 \%$ at $25.5 \mathrm{~mW}$, respectively, for $4 \times$ and $8 \times$ recording speed in FVD-R format.

\section{References}

[1] J. Tominaga, S. Haratani, K. Uchiyama, S. Takayama, Jpn. J. Appl. Phys. 31 (1992) 2757.

[2] K. Kimura, E. Ohno, Jpn. J. Appl. Phys. 28 (1989) 2223.

[3] H. Inoue, K. Mishima, M. Aoshima, H. Hirata, T. Kato, H. Utsunomiya, Jpn. J. Appl. Phys. 42 (2003) 1059.

[4] Y. Hosoda, T. Izumi, A. Mitsumori, F. Yokogawa, S. Jinno, H. Kudo, Jpn. J. Appl. Phys. 42 (2003) 1040.

[5] B.M. Chen, H.F. Chen, R.L. Yeh, J.M. Chung, Jpn. J. Appl. Phys. 43 (2004) 5018. 